\title{
The fish community in Zmiinyi Island waters: structure and determinants
}

\section{Sergey Snigirov, Oleksandr Goncharov \& Sergiy Sylantyev}

\section{Marine Biodiversity}

ISSN 1867-1616

Volume 42

Number 2

Mar Biodiv (2012) 42:225-239

DOI 10.1007/s12526-012-0109-4

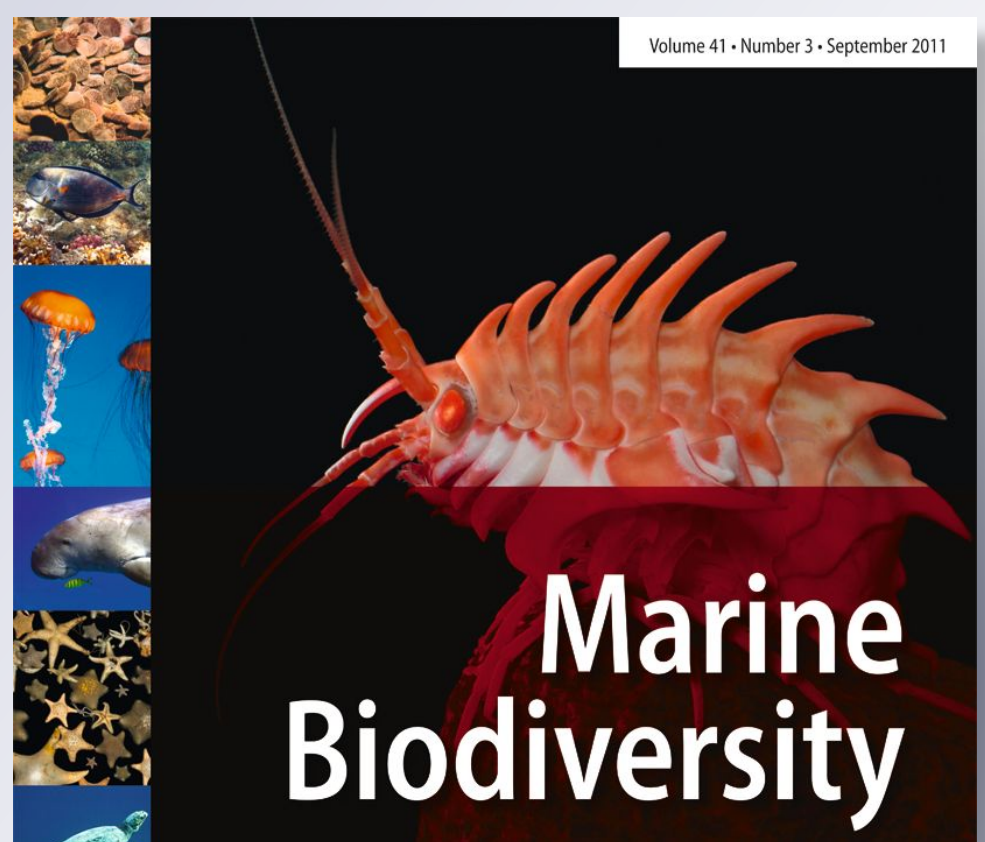

A Journal of the

Senckenberg Research Institute

Special Issue

Arctic Marine Biodiversity

under Change

Guest Editors:

Haakon Hop · Tore Haug.

Stig Falk-Petersen
Stakon Hop

SENCKENBERG

Springer

\section{包 Springer}


Your article is protected by copyright and all rights are held exclusively by Senckenberg, Gesellschaft für Naturforschung and Springer. This e-offprint is for personal use only and shall not be self-archived in electronic repositories. If you wish to self-archive your work, please use the accepted author's version for posting to your own website or your institution's repository. You may further deposit the accepted author's version on a funder's repository at a funder's request, provided it is not made publicly available until 12 months after publication. 


\title{
The fish community in Zmiinyi Island waters: structure and determinants
}

\author{
Sergey Snigirov • Oleksandr Goncharov • \\ Sergiy Sylantyev
}

Received: 24 July 2011 /Revised: 19 December 2011 / Accepted: 3 January 2012 / Published online: 7 February 2012

(C) Senckenberg, Gesellschaft für Naturforschung and Springer 2012

\begin{abstract}
The fish fauna assemblage and its association with environmental factors in the waters around Zmiinyi Island in the Black Sea were examined based on biological and hydrological data collected in the period 2003-2011. The aims of the study were to identify the fish species composition and community parameters in the area, to determine the contribution of different environmental factors to seasonal variations of the fish assemblage, and to assess the Danube outflow-induced shaping of the fish species community on a seasonal time scale. A total of 58 species belonging to 35 families were collected; most were of Mediterranean origin. The most abundant species were Atherina boyeri, Aidablennius sphynx, Engraulis encrasicolus, Merlangius merlangus, Neogobius melanostomus, Sprattus sprattus and Trachurus mediterraneus. The fish community in the area studied displayed pronounced seasonal variations. Mediterranean species were the group which predominantly determined the directions of such variations
\end{abstract}

Oleksandr Goncharov and Sergiy Sylantyev contributed equally to the work.

\section{S. Snigirov}

Biological Department, Odesa National Mechnikov University,

2 Shampanskiy lane,

Odesa 65058, Ukraine

\section{O. Goncharov}

Institute of Biology of Southern Seas, Odesa Branch,

37 Pushkinskaya st.,

Odesa 65125, Ukraine

S. Sylantyev $(\bowtie)$

DCEE, Institute of Neurology, University College London,

Queen Square,

London WC1N 3BG, UK

e-mail: s.sylantyev@ucl.ac.uk and the overall community structure. Data analysis revealed temperature and salinity to be the most important factors influencing the community assemblage. Despite the substantial amount of freshwater runoff from the adjacent Danube Delta, seasonal variations in this factor did not cause significant fluctuations in fish fauna composition.

Keywords Zmiinyi Island · Black Sea · Danube runoff · Fish fauna $\cdot$ Species diversity

\section{Introduction}

Relationships between the abundance of fish taxa and abiotic factors such as salinity, temperature, and dissolved oxygen have been the subject of numerous studies (Woodhead 1994; Thiel et al. 1995; Maes et al. 1998; Griffiths 2001; Jaureguizar et al. 2004; Harrison and Whitfield 2006). These studies have shown that fish communities display changes in the composition and relative abundance of species over a seasonal time scale and, as a rule, these changes are influenced by fluctuations in environmental factors.

Zmiinyi Island, located some $35 \mathrm{~km}$ seaward from the Danube Delta in the north-western part of the Black Sea (NWBS) is the only non-coastal island in the Black Sea. The rocky underwater landscape around the island, together with several sandy areas, is in striking contrast to the extensive sand and silt flats that are typical of the seafloor of the NWBS, and provides a habitat for sustainable phyto- and zoobenthos communities. Therefore, this suggests that the Zmiinyi Island area should be an attractive habitat for different ecological groups of fishes (demersal and pelagic species) due to its relatively high biological productivity. Such attractiveness allows an in situ comparative faunistic study of the two main zoogeographical groups which 
comprise the Black Sea ichthyofauna, i.e. species of Mediterranean origin, and non-Mediterranean fishes which are widely believed to have a different pattern of environmental preferences (Slastenenko 1959; Zaitsev 1992). The continuous arrival and incorporation of various new fish species from the Mediterranean ("mediterranization") observed during the last several decades (Puzanov 1965; Tokarev and Shulman 2007) presents a hypothesis concerning the determinative role of Mediterranean species in shaping the fish community parameters in Zmiinyi Island waters.

In the NWBS, seasonal changes of the abovementioned environmental factors are accompanied by large fluctuations in the volume of freshwater runoff, with about $80 \%$ of total outflow into the Black Sea discharged there. The Danube River accounts for about $75 \%$ of freshwater ejection into the NWBS, or approximately $230 \mathrm{~km}^{3}$ per year (Mee 1992). This makes plausible the hypothesis that freshwater runoff from rivers (and especially from Danube) is a substantial parameter determining fish diversity in the Black Sea, particularly in the NWBS. Such a hypothesis was tested and confirmed for interannual and interdecadal time periods (Aubrey et al. 1996; Daskalov 2003; Zaitsev et al. 2006; Oguz and Gilbert 2007). However, to the best of our knowledge, the impact that river outflow has on fish diversity in the NWBS has never been studied on a seasonal time scale. The geographical position of Zmiinyi Island just in front of the Danube Delta makes the adjacent waters an appropriate area for such a study.

Seasonal migrations of pelagic fishes from the northern and central parts of the sea to the southern coastal waters and to the Sea of Marmara is a well-known characteristic of Black Sea ichthyofauna (Galtsoff 1924; Chaschin 1996; Artüz 1999; Zengin and Dinçer 2006). These migrations display a well-founded correlation with water temperature and give a plausible explanation for the variation of the pelagic species abundance. Such migrations may also explain a substantial part of the fluctuations in overall fish community composition in the NWBS. However, to the best of our knowledge, there are still no data on seasonal migrations of demersal species in the NWBS. Therefore, to dissect possible mechanisms of changes in the catches, one should take into account fluctuations of the gear catchability due to variations of fish mobility at different temperatures (Swain et al. 2000).

Despite the unique characteristics of the area and intensive studies of the Black Sea biodiversity in recent decades, the present work is, to our best knowledge, the first formal study of fish fauna in Zmiinyi Island waters.

Therefore, the objectives of our research were:

1. To characterize the diversity of fish species in the Zmiinyi Island area and its dependence on the main environmental factors (temperature, salinity, dissolved oxygen).
2. To clarify seasonal changes of composition in Mediterranean and non-Mediterranean species groups.

3. To test the hypothesis that fluctuations of the overall fish community parameters are mainly due to the changes in Mediterranean species richness and abundance.

4. To find out to what extent the seasonal composition of fish species detected in study area is influenced by the Danube outflow.

\section{Materials and methods}

Study area and fish sampling

The waters around Zmiinyi Island $\left(45^{\circ} 15^{\prime} 18^{\prime \prime} \mathrm{N}, 30^{\circ} 12^{\prime} 15^{\prime \prime} \mathrm{E}\right)$ were tested at 22 sampling sites, at depths from 1.5 to $23 \mathrm{~m}$; the overall research area was approximately $2 \mathrm{~km}^{2}$ (Fig. 1). From 2003 to 2011, several expeditions were conducted to collect environmental and ichthyological data (902 individual samples); cumulatively, data collection lasted for 33 months, with samples taken in all months across the year.

Each biological sample consisted of catches at three to four coastal sites (within the 5-m isobath) and two to three deepwater sites (outside the 5-m isobath) (Fig. 1). In terms of species composition, there were no differences between catches at different coastal sites and at different deepwater sites. The geographical coordinates of the sampling sites were controlled using a GPS navigator. At deepwater sites, sampling was performed using fixed $100-\mathrm{m}$-long gillnets having a mesh size of $20 \mathrm{~mm}$, and $3 \mathrm{~m}$ long having a mesh size of $8 \mathrm{~mm}$, running parallel to the coastline. Sampling at coastal sites was carried out using the same types of nets and, in addition, manually using an 8-mm-mesh landing net. Sampling nets were lowered from the boat and fixed to the seabed by scuba divers. After $24 \mathrm{~h}$, the nets were removed from the water and fish specimens were fixed with $4 \%$ formaldehyde. Taxonomic identifications were made in accordance with Svetovidov (1964), Nelson (1994), Jennings (1996), Miller and Loates (1997), and Serena (2005), taking into account later reclassifications (Almada et al. 2008). Zoogeographical grouping (Mediterranean and non-Mediterranean species) was performed according to Slastenenko (1959), Zaitsev (1992), Miller and Loates (1997), and Froese and Pauly (2011).

Environmental data collection

Temperature, salinity, and oxygen concentration were measured at sampling sites at midday on each day of sampling; water samples for salinity and oxygen concentration testing were taken using a twin bathometer. Data on the Danube 
Fig. 1 Geographical location of Zmiinyi Island and sampling sites in its vicinity. Upper: dashed line the border of NWBS. Lower: $C$ coastal sites, $D$ deepwater sites
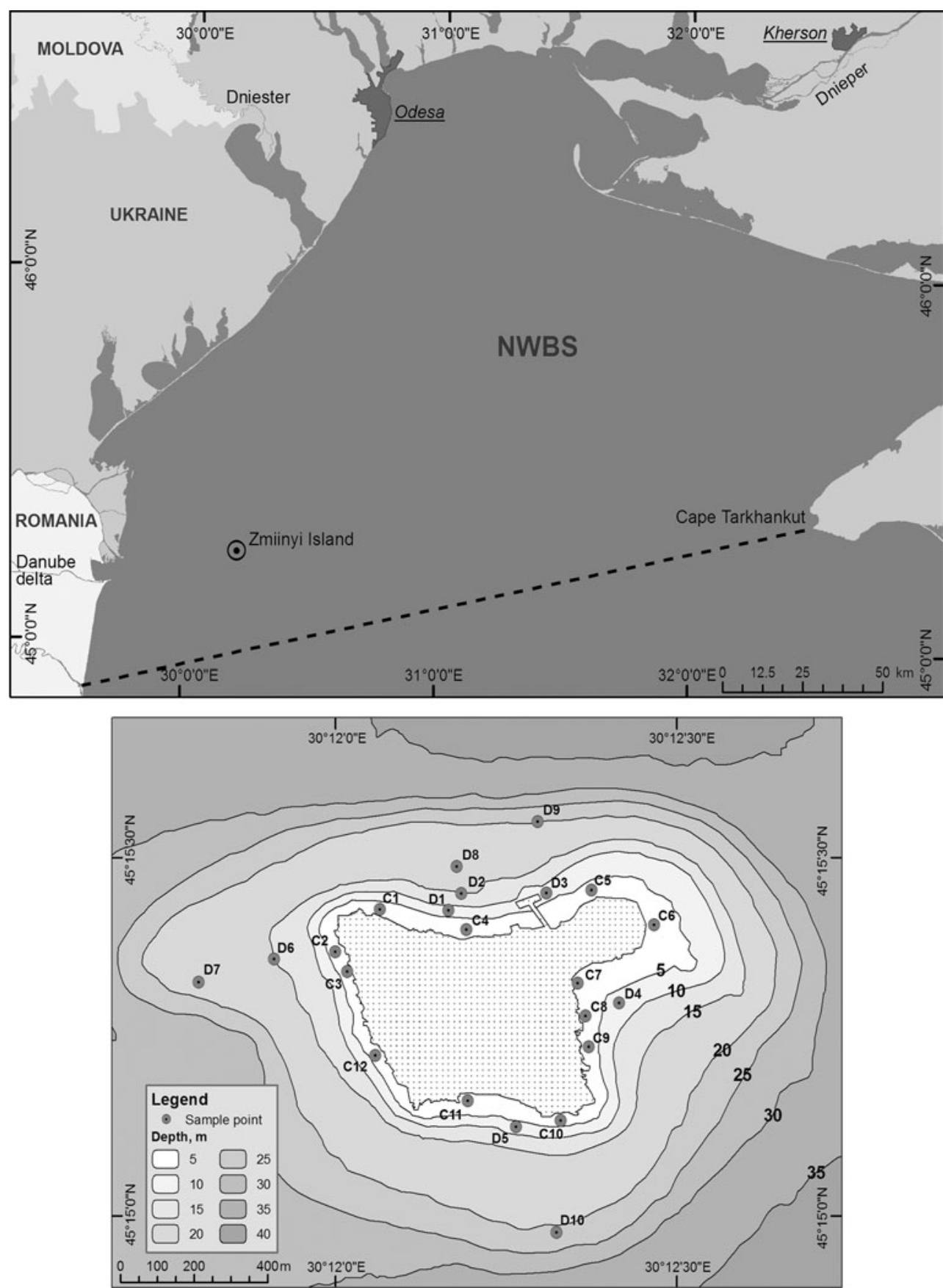

outflow for 2003-2011 were obtained from the database of the Danube Hydrometeorological Observatory (Izmail, Ukraine).

\section{Data analysis: general fish diversity}

For the general characterisation of species diversity in the study area, we used data collected over the all 33 months of field work. Numerical calculations were performed with the Mathematica 8.0.1, XLStat-2010, and CANOCO 4.5 software.
Since in our study area the abundance of species differed by two-three orders of magnitude, we fitted the species accumulation curve with a modified Clench's equation which was shown to be the most adequate for this type of community (Soberon and Llorente 1993):

$N=\frac{a \times n}{1+b \times n}$,

where $\mathrm{N}$ is the number of species detected, $\mathrm{n}$ is the number of samples, and $a$ and $b$ are fitting constants; 
whence the total number of species in fish fauna was estimated as

$\lim _{n \rightarrow \infty}\left(\frac{a \times n}{1+b \times n}\right)$.

For graphical representation of the variations in fish assemblage structure between different months, cluster analysis and multidimensional scaling (MDS) were used. Initially, the Bray-Curtis dissimilarity index was calculated based on density data such as the dissimilarity of fish assemblage structure between months. Then, a dissimilarity matrix was generated and subjected to an average linkage clustering method in order to generate a dissimilarity dendrogram for the months, and also to carry out MDS to check the grouping of months by placing them on an ordination plot (Horinouchi 2009).

The Canonical Correspondence Analysis (CCA) was used to find out the relative importance of environmental variables determining the value of the species abundance (Braak 1986; Braak and Verdonschot 1995). This method was chosen since it is less susceptible than other ordination methods to nonlinearities in the data matrix, and because it explicitly assumes nonlinear (Gaussian) distributions of species quantity along the environmental gradients (Braak 1994; Braak and Verdonschot 1995). CCA was applied to the overall fish data matrix (dependent set) and the environmental data matrix (independent set) in order to elucidate the relationships between biological assemblages of species and the environmental variables.

The XLStat software provides the "Forward Selection" function with the built-in "Monte-Carlo Permutation Test" that ranks the environmental variables separately. The fit of a parameter is the eigenvalue of the CCA with this parameter as the only variable. In this procedure, the variable with the highest eigenvalue is separated, and at each further step the next variable is selected which adds most to the explained variance of the species data. At each step, it is tested by 1,000 random permutations to test whether the parameter added is statistically significant; permutations were performed using the Monte-Carlo sampling technique. We set the limit at 1,000 since this number of permutations yields an effective approximate test in that algorithm (Edgington 1995).

Such a procedure allows the description and permits the visualization of the differential environmental niches preferred by taxa via an ordination diagram (Braak 1994). Interset correlations of this analysis were used to clarify which environmental variables were most important in determining the value of the species abundance (Braak and Verdonschot 1995). The contribution of each variable was assessed through correlations between environmental variables (temperature, salinity, dissolved oxygen, volumes of the Danube outflow) and the CCA axes (Akin et al. 2005).
Data analysis: seasonal changes

To characterize the sequential seasonal changes in the fish community, we used a dataset collected over the continuous 13-month period of observation from April 2005 to April 2006.

The fish community parameters: species richness, diversity and evenness were estimated as a summary of distribution and abundance of fish species. Species richness was considered to be the total number of species recorded at each month, and diversity was evaluated using the Simpson complement index, i.e. 1-D, where

$D=\frac{\sum_{i=1}^{S} n_{i}\left(n_{i}-1\right)}{N(N-1)}$.

Here, $\mathrm{S}$ is the number of species, $\mathrm{N}$ is the total number of fishes caught, and $\mathrm{n}$ is the number of individuals of each species. This index was chosen since it is less sensitive to sample size than other biodiversity indices (Smith and Wilson 1996; Lande et al. 2000). To assess species evenness, we used the Simpson evenness index $E_{1 / D}=\frac{1 / D}{S}$, which was shown to be independent of species richness (Smith and Wilson 1996).

We used a multivariate linear regression to examine the relationship between species richness as the dependent variable and environmental factors as independent variables. To estimate colinearity between variables, we calculated the variance inflation factor (VIF): if this is lower than 10 for all variables, a multivariate regression could be considered as an appropriate method for the data description (Kutner 2004). For this model, we have also used forward stepwise selection by the least-squares method. At each iteration, the variable showing the highest partial correlation with the dependent variable was determined and then included in the model.

To assess the temperature-conditioned fluctuations of species catchability, we adapted the descriptive algorithm introduced by Ward and Myers (2005), which is based on the generalized linear mixed effect models (Wolfinger and O'Connell 1993). The catch of each species in a sample at temperature $t$ was assumed to follow an overdispersed Poisson distribution with a mean of $\mu_{\mathrm{t}}$. Thus, for each species group, the model predicts the mean catch $\mu_{\mathrm{t}}$ using a log dependence:

$\log \left(\mu_{t}\right)=\gamma_{0}+\gamma_{1} t+\gamma_{2} t^{2}+\gamma_{3} t^{3}+\log \left(E_{t}\right)$

where the regression coefficients $\gamma_{0-3}$ are the parameters estimated for each species with a Newton-Raphson iterational method, and $E_{t}$ is the number of samples taken at a given temperature interval (i.e. fishing effort). 
The method includes a random model that accounts for variations in the local abundance of each species and assumes that the $\log$ abundance of species followed a normal distribution. The regression coefficients $\gamma_{0-3}$ describe how catchability changes with temperature. The cubic model satisfactorily characterized most of the variation in temperature; including additional $\gamma$ parameters did not induce a significant increase in the fit of the model as was judged by a likelihood ratio test.

We then used estimates of parameters from the previous equation to calculate the catchability q of each species as a function of temperature:

$q=\exp \left(\alpha+\gamma_{1} t+\gamma_{2} t^{2}+\gamma_{3} t^{3}\right)$,

where $\alpha$ was chosen such that the mean q equals one over the temperature interval considered.

Since the estimation significance in these type of methods decreases rapidly with a decrease of $\mu_{\mathrm{t}}$ (Wolfinger and O'Connell 1993), i.e. the number of individuals caught, we used for the catchability estimation only the dominant species (more than 100 individuals caught during each year).

Data were represented as a mean \pm SEM. Spearman correlation coefficient $\left(r_{\mathrm{s}}\right)$, coefficient of determination $R^{2}$, adjusted $R^{2}$ for the multivariate regression model and the two-sample Kolmogorov-Smirnov test were used as indicated.

\section{Results}

Environmental analysis

The values of the environmental variables displayed evident differences between months. Maximum values of temperature and salinity in a period from 2003 to 2011 were observed during the time interval from July to September; maximum oxygen concentration was observed from December to March; and maximum values of the Danube outflow were recorded in April, thus ensuring arrival during this month of three out of four freshwater species detected in the study area (Fig. 2). Values recorded over the continuous observation period (April 2005-April 2006) did not display the different general profile compared to the corresponding averaged variables for the 2003-2011 period ( $P=0.821$ for temperature, $P=0.906$ for dissolved oxygen, $P=0.893$ for salinity, $P=0.794$ for the Danube outflow volumes; two-sample Kolmogorov-Smirnov test). Surprisingly, for the period of our research, we did not detect any significant correlation between the monthly volumes of Danube outflow and salinity $\left(r_{\mathrm{s}}=-0.452, P=0.296\right)$, water temperature $\left(r_{\mathrm{s}}=-0.303, \mathrm{P}=0.577\right)$, or oxygen concentration $\left(r_{\mathrm{s}}=0.264, P=0.598\right)$.
Overall fish community composition

In the 902 samples, we captured 40,849 individuals, corresponding to 15 orders, 35 families, 48 genera, and 58 species (Table 1). The most diverse order was Perciformes with 14 families, 22 genera, and 28 species. Most diverse genera were Sygnathus (4 species), Parablennius and Neogobius (3 species), Symphodus, Liza and Gobius (2 species). Each of the other 42 genera contains a single species. The most abundant species were (in descending order): Atherina boyeri, Aidablennius sphynx, Engraulis encrasicolus, Neogobius melanostomus, Sprattus sprattus, Merlangius merlangus and Trachurus mediterraneus, which accounted for $76.8 \%$ of the total number of individuals collected.

Twelve of the detected fish species are included in the Red Book of Ukraine, seven species are under the protection of the Convention on the Conservation of European Wildlife and Natural Habitats (Bern Convention), and twelve species are included in the IUCN Red List.

\section{General fish diversity}

Fitting of the cumulative species detection curve (Fig. 3) yielded a value of 61 as an estimation of total species number in the study area. Therefore, in our field research, we revealed more than $95 \%$ of ichthyofauna composition in the waters of the island.

The dissimilarity dendrogram showed a clear grouping of months into two clusters with a dissimilarity index of 0.592 : "Cold season" (November-March) and "Warm season" (all other months); the MDS ordination demonstrated a similar pattern (Fig. 4).

In addition, we have used CCA to analyze the influence of environmental factors on fish species abundance over the period of research. The first two axes of the CCA ordination map explained $86.57 \%$ of the cumulative constrained variance in the species-environment bi-plot (axis 1, 60.19\%; axis $2,24.38 \%$ ). The trends of the main environmental gradients were simultaneously related to both the first and second ordination axes (Fig. 5). According to the interset correlations, temperature and salinity were the most important environmental variables, whereas dissolved oxygen and, especially, Danube outflow volumes displayed much lower importance in the structuring of the fish community (for more details on CCA results, refer to the caption of Fig. 5). Thus, temperature and salinity together form the main sample ordination gradient going from the origin of coordinates to the second ordination quadrant (positive values on the axis 2 , negative values on the axis 1). Notably, Mediterranean species experience the greatest positive influence of this gradient. Contrary to this, species located in the first and fourth ordination quadrants (along the positive direction of axis 1) are almost exclusively non-Mediterranean and 

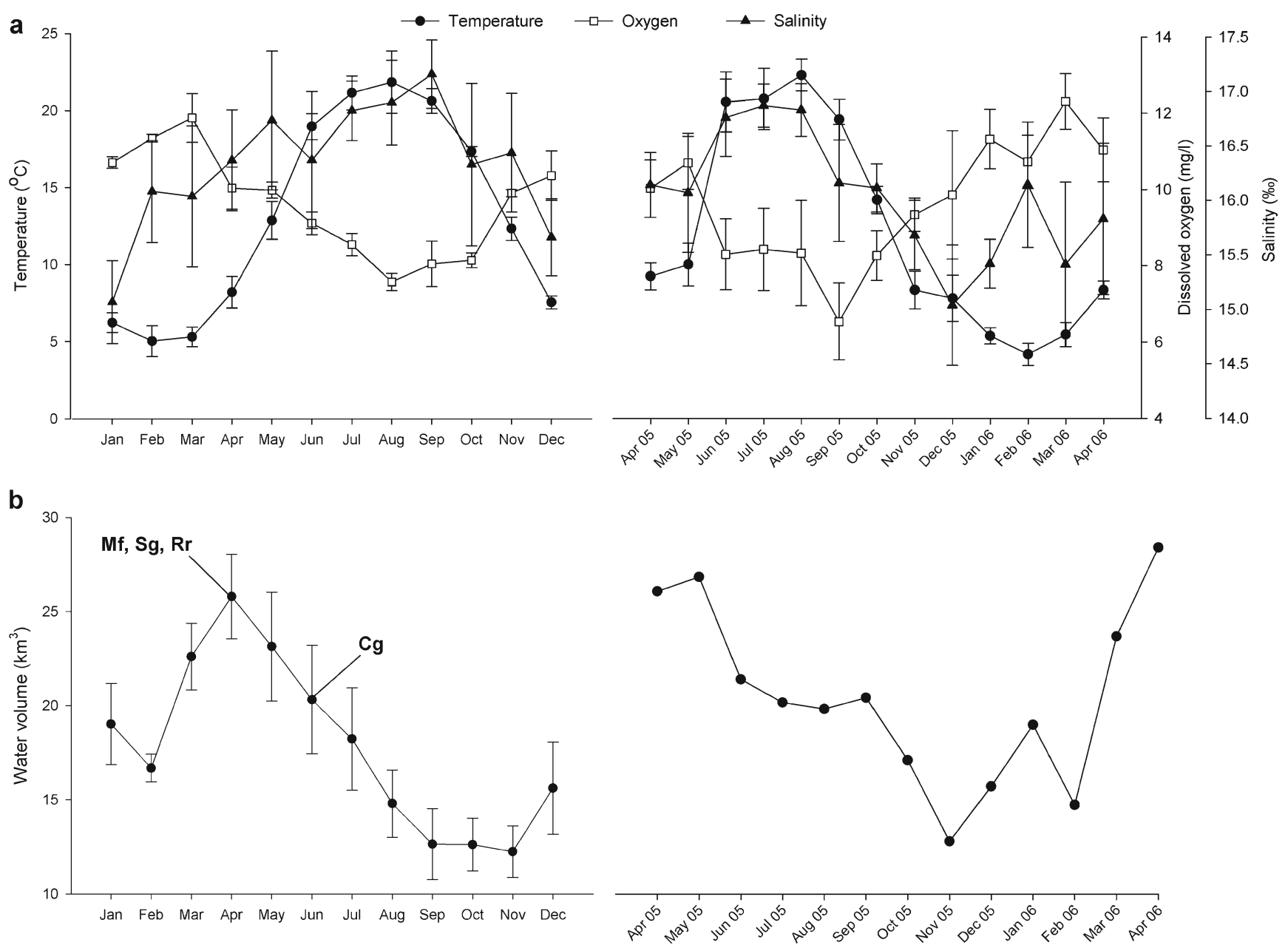

Fig. 2 Monthly values of environmental variables. a Left panel average values of temperature, salinity and oxygen concentration over the period 2003-2011. Right panel same data for the period of continuous observation of the fish community. b Left panel Danube outflow

volumes over the period 2003-2011; species codes (see Table 1) denote months when correspondent freshwater species were detected in Zmiinyi Island waters. Right panel same data for the period of continuous observation. Vertical axes apply to both right and left panels

were collected mainly during the "Cold season". The area between these two extremes (around the origin of coordinates) contains species found throughout the year.

Seasonal changes in fish assemblage

To clarify the influence of environmental factors on the fish community on a seasonal time scale, we performed a multivariate linear regression analysis of a dataset for the period of April 2005-April 2006 (Fig. 6). Results of the analysis are given in Table 2.

Species richness in all three models (for overall species richness, Mediterranean and non-Mediterranean species) was significantly positively correlated with water temperature. Correlation between species richness and salinity was also positive and significant for overall and Mediterranean species richness, yet not significant for non-Mediterranean species. In contrast, oxygen concentration turned out to be significantly negatively correlated with overall and Mediterranean species richness, whereas correlation with non-Mediterranean species richness was not significant. In turn, Danube outflow did not display significant correlation with species richness in any of three models. The coefficient of multiple determination, $R^{2}$, showed a highest value of 0.943 for the Mediterranean species model, indicating the maximal sensitivity of this group to the fluctuations in environmental conditions. The VIF values were lower than 10 in all cases, indicating a moderate level of colinearity between independent variables. However, the highest VIF values for oxygen concentration in all three models suggest prudence when interpreting the influence of this variable on the fish community.

To further analyze fish community behavior, we investigated fluctuations in species diversity and evenness (Fig. 7). Species diversity exhibited clear seasonal changes throughout 
Table 1 Taxonomic composition of Zmiinyi water area fish fauna, its zoogeographical characteristics and species occurrence

Taxonomic composition (codes)
Zoogeographical group
Species occurrence

Deepwater catch

Coastal catch

\section{Rajiformes}

Dasyatidae

Dasyatis pastinaca (Linnaeus, 1758) (Dp)

Rajidae

Raja clavata Linnaeus, $1758(\mathrm{Rc})^{\mathrm{c}}$

Squaliformes

Squalidae

Squalus acanthias Linnaeus, $1758(\mathrm{Sa})^{\mathrm{c}}$

$1 b$

Acipenseriformes

Acipenseridae

Acipenser stellatus Pallas, 1771 (As) ${ }^{\mathrm{a}, \mathrm{b}, \mathrm{c}}$

Huso huso (Linnaeus, 1758) (Hh) ${ }^{\mathrm{a}, \mathrm{b}, \mathrm{c}}$

Clupeiformes

Clupeidae

Alosa maeotica (Grimm, 1901) (Alm)\#

Sprattus sprattus (Linnaeus, 1758) (Ss)

3

Engraulidae

Engraulis encrasicolus (Linnaeus, 1758) (Ee)

Cypriniformes

Cobitidae

Misgurnus fossilis (Linnaeus, 1758) (Mf)

Cyprinidae

Carassius gibelio (Bloch, 1782) (Cg)

Rutilus rutilus (Linnaeus, 1758) (Rr)

Gadiformes

Lotidae

Gaidropsarus mediterraneus (Linnaeus, 1758) (Gm)

Gadidae

Merlangius merlangus (Linnaeus, 1758) (Mm)

Beloniformes

Belonidae

Belone belone (Linnaeus, 1761) (Bb)

Ateriniformes

Aterinidae

Atherina boyeri Eichwald, $1838(\mathrm{Ab})$

Syngnathiformes

Syngnathidae

Hippocampus guttulatus Cuvier, $1829(\mathrm{Hg})^{\mathrm{a}, \mathrm{b}, \mathrm{c}}$

Syngnathus abaster Risso, 1827 (Sya) ${ }^{\mathrm{b}}$

Syngnathus tenuirostris Rathke, 1837 (St) ${ }^{\mathrm{a}}$

Syngnathus typhle Linnaeus, 1758 (Sty)

Syngnathus variegatus Pallas, $1814(\mathrm{~Sv})^{\mathrm{a}}$

Scorpaeniformes

Scorpaenidae

Scorpaena porcus Linnaeus, 1758 (Sp)

Triglidae

Chelidonichthys lucernus (Linnaeus, 1758) (Cl ${ }^{\mathrm{a}, \mathrm{c}}$
$1 \mathrm{~b}$
$++$

$++$

$++$

$++$

$+++$

$+++$

$+++$

$+++$

$++$

$+++$

$+$

$+$

$+$

$+$

$+$

$+++$ 
Table 1 (continued)

Taxonomic composition (codes)

Zoogeographical group

Species occurrence

Deepwater catch

Coastal catch

Perciformes

Pomatomidae

Pomatomus saltatrix (Linnaeus, 1766) (Pos) ${ }^{\mathrm{c}}$

1a

Carangidae

Trachurus mediterraneus (Steindachner, 1868) (Tm)

Centracanthidae

Spicara maena Rafinesque, 1810 (Sm)

Sciaenidae

Sciaena umbra Linnaeus, $1758(\mathrm{Su})^{\mathrm{a}}$

Umbrina cirrosa (Linnaeus, 1758) (Uc) $)^{\mathrm{a}, \mathrm{b}}$

Scombridae

Sarda sarda (Bloch, 1793) $(\text { Sas })^{\mathrm{c}}$

Mullidae

Mullus barbatus ponticus Essipov, 1927 (Mub)

Pomacentridae

Chromis chromis (Linnaeus, 1758) $(\mathrm{Cc})^{\mathrm{a}, \mathrm{c}}$

Labridae

Symphodus cinereus (Bonnaterre, 1788)\# (Sc)

Symphodus ocellatus (Forsskal, 1775)\# (So)

Trachinidae

Trachinus draco Linnaeus, 1758 (Td)

Uranoscopidae

Uranoscopus scaber Linnaeus, 1758 (Us)

Blennidae

Aidablennius sphynx (Valenciennes, 1836) (Ais)\#

Parablennius sanguinolentus (Pallas, 1814) (Ps) $\#^{\mathrm{b}}$

Parablennius tentacularis (Brünnich, 1768) (Pt)\#

Parablennius zvonimiri (Kolombatovic, 1892) (Pz)\#

Salaria pavo (Risso,1810) (Sap)

Ophidiidae

Ophidion rochei Müller, 1845 (Or)

Ammodytidae

Gymnammodytes cicerellus (Rafinesgue, 1810) (Gc)

Gobiidae

Aphia minuta (Risso, 1810) (Am)

Benthophilus stellatus (Sauvage, 1874) (Bs) ${ }^{\mathrm{a}, \mathrm{c}}$

Gobius niger Linnaeus, 1758 (Gn) $\#^{\mathrm{b}}$

Gobius paganellus Linnaeus, 1758 (Gp)\#

Mesogobius batrachocephalus (Pallas, 1814) (Mb)

Neogobius cephalargoides (Pinchuk, 1976) (Nc)

Neogobius melanostomus (Pallas, 1814) (Nm)

Neogobius ratan (Nordmann, 1840) $(\mathrm{Nr})^{\mathrm{c}}$

Proterorhinus marmoratus (Pallas, 1814) (Pm)

Mugiliformes

Mugilidae

Liza aurata (Risso, 1810) (La)

Liza haematocheila (Temmnick \& Schlegel, 1845) (Lh) 1a

1a

1a

1a

$1 \mathrm{a}$

1a

$1 \mathrm{a}$

$1 \mathrm{a}$

1a

1a

1a

1a

1a

1a

1a

$1 b$

1a

2

1a

1a

2

2

2

2

2

1a

5
$++$

$+++$

$++$

$+++$

$+$

$+++$

$+++$

$+++$

$+++$

$+$

$++$

$++$

$+$

- -

$++$

$+$

$+++$

$+$

$+++$

$+++$

$++$

$+++$

$+++$ 
Table 1 (continued)

Taxonomic composition (codes)

Zoogeographical group

Species occurrence

Deepwater catch

Coastal catch

\begin{tabular}{|c|c|c|c|}
\hline \multicolumn{4}{|l|}{ Gobiesociformes } \\
\hline \multicolumn{4}{|l|}{ Gobiesocidae } \\
\hline Diplecogaster bimaculata (Bonnaterre, 1788) $(\mathrm{Db})^{\mathrm{a}}$ & $1 \mathrm{a}$ & -- & ++ \\
\hline Mirbelia candolii (Risso, 1810) (Mc) ${ }^{\mathrm{a}}$ & 1a & -- & ++ \\
\hline \multicolumn{4}{|l|}{ Pleuronectiformes } \\
\hline \multicolumn{4}{|l|}{ Pleuronecthidae } \\
\hline Platichthys flesus (Linnaeus, 1758) (Pf) & $1 \mathrm{~b}$ & + & + \\
\hline \multicolumn{4}{|l|}{ Scophthalmidae } \\
\hline Psetta maxima maeotica (Pallas, 1814) $(\mathrm{Psm})^{\mathrm{c}}$ & $1 \mathrm{~b}$ & + & ++ \\
\hline \multicolumn{4}{|l|}{ Soleidae } \\
\hline Pegusa lascaris (Risso, 1810) (Pl) & $1 \mathrm{a}$ & -- & + \\
\hline \multicolumn{4}{|l|}{ Siluriformes } \\
\hline \multicolumn{4}{|l|}{ Siluridae } \\
\hline Silurus glanis Linnaeus, $1758(\mathrm{Sg})$ & 4 & -- & - \\
\hline
\end{tabular}

$1 a$ Mediterranean species, $1 b$ Boreal-Atlantic relicts, 2 brackishwater species, 3 anadromous species, 4 freshwater species, 5 recently introduced species, \# Tethys relicts.

- - Species not found, - very rare species (less than 10 individuals caught during whole period of observations), + rare species (less than 10 individuals caught during one year of observations), ++ common species (up to 100 individuals caught during 1 year of observations), +++ dominant species (more than 100 individuals caught during 1 year of observations)

${ }^{\mathrm{a}}$ Red Book of Ukraine, ${ }^{\mathrm{b}}$ Bern Convention, ${ }^{\mathrm{c}}$ IUCN Red List v. 2011.2.

the year, with two relatively stable periods: constantly high values in an interval between June and October and constantly low values in an interval between December and March. Species evenness displayed comparatively stable values from April to November 2005, a gradual increase during the winter months with a peak in February, followed by a subsequent decrease. Thus, species diversity significantly correlated with

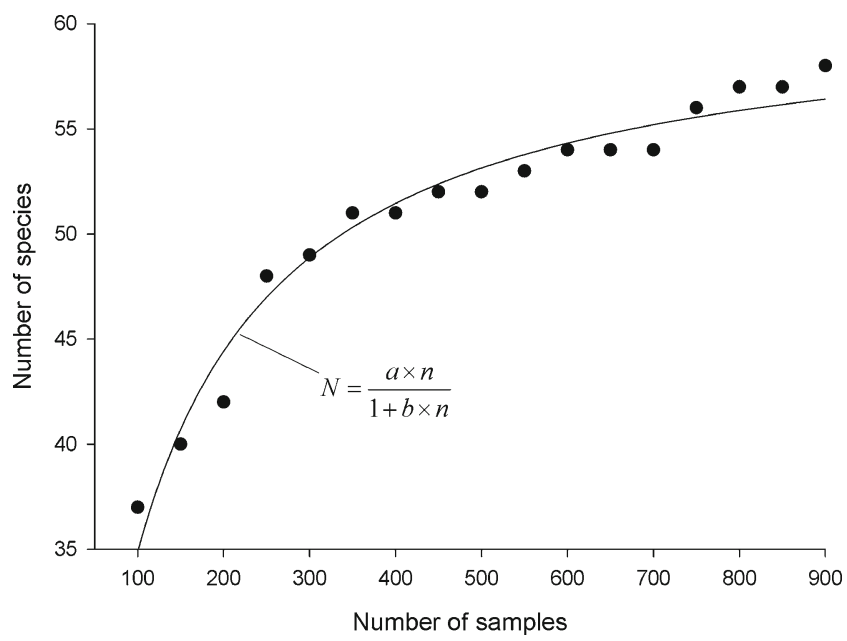

Fig. 3 Species accumulation curve. Dots number of species detected during fieldwork. Values of coefficients in a curve-fitting equation: $a=$ $0.8129, b=0.0133 ; R^{2}=0.9995$ overall richness $\left(r_{\mathrm{s}}=0.933, P=0.007\right)$ but not with species evenness $\left(r_{\mathrm{s}}=-0.544, P=0.058\right)$. To evaluate the input of two species groups into species diversity, we calculated the correlation strengths between overall species diversity and richness of Meditrranean and non-Mediterranean species. In both cases, we obtained significant positive correlation coefficients: $r_{\mathrm{s}}=0.969, P=0.003$ for Mediterranean species and $r_{\mathrm{s}}=0.64, P=0.038$ for non-Mediterranean fishes.

To test for possible changes in our gear catchability at different temperatures, we calculated catchability coefficients for the 12 dominant species of two ecological groups (6 pelagic and 6 demersal) of Mediterranean and nonMediterranean fishes (Fig. 8). We found a considerable difference in a temperature-related distribution of the $\mathrm{q}$ values between different species groups: q lowered at a low temperature for all pelagic and Mediterranean demersal species, whereas for demersal non-Mediterranean species, $\mathrm{q}$ was relatively stable throughout the temperature range.

\section{Discussion}

Environmental analysis

In Zmiinyi Island waters, measured environmental variables showed pronounced seasonal variation; the maximum 


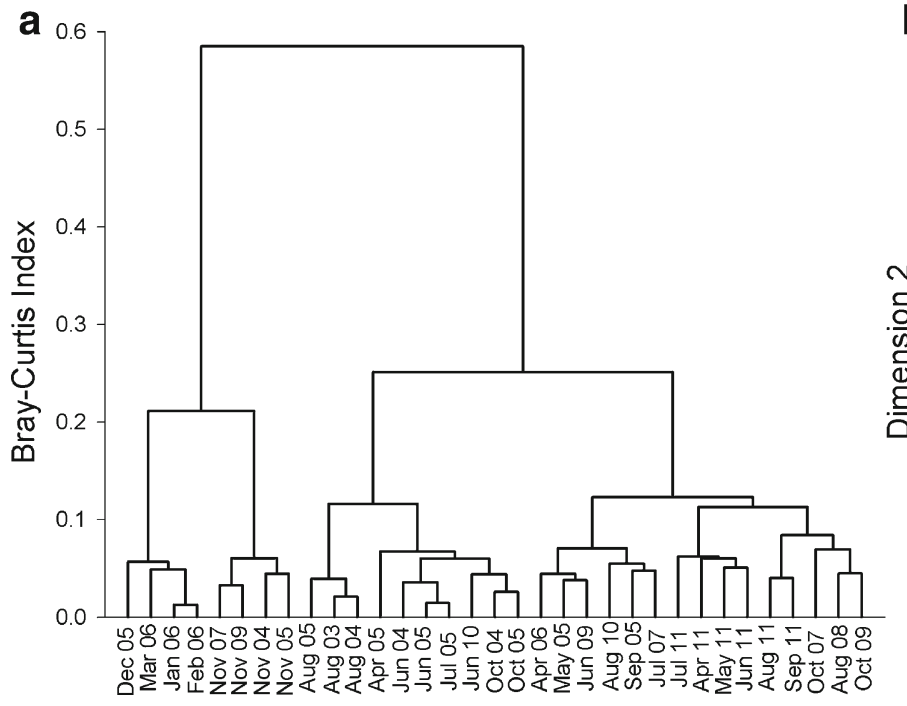

Fig. 4 Graphical representation of the seasonal variations in fish assemblage structure. a Dendrogram of months-clustering; $\mathbf{b}$ plot of two-dimensional ordination of months from MDS based on the Bray-

values of temperature and salinity during the June to September period were accompanied by the smallest concentrations of dissolved oxygen, probably due to the decreased solubility at higher temperatures and algal blooms

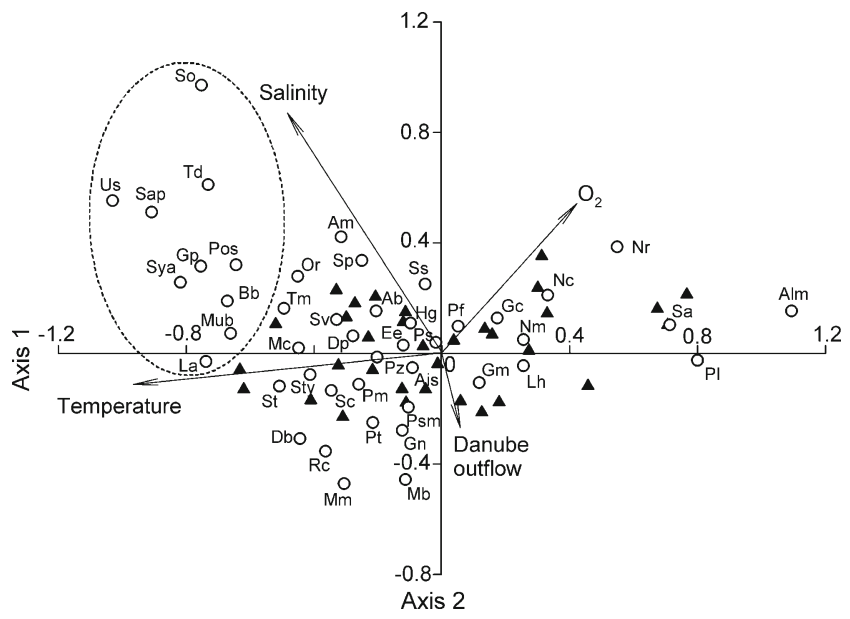

Fig. 5 Ordination diagram based on a CCA of species abundance throughout the period 2003-2011. The significance of the effect of the four environmental variables verified by a Monte-Carlo permutation test, $P=0.006$. Length and direction of arrows indicate the relative importance and direction of change in the environmental variables. Open circles species; species codes correspond to those given in Table 1. Black triangles months when sampling was performed. Dashed ellipse the habitat niche of the species of Mediterranean origin that are most sensitive to the gradient generated by temperature and salinity. Scores for the interset correlation between environmental variables and species for axes 1 and 2, respectively: for temperature -0.83 and -0.12 ; for salinity: -0.47 and 0.65 ; for oxygen concentration: 0.32 and 0.31 ; for the Danube outflow: 0.08 and -0.17 . Rare species (less than five individuals collected during the whole period of research) are excluded from this analysis

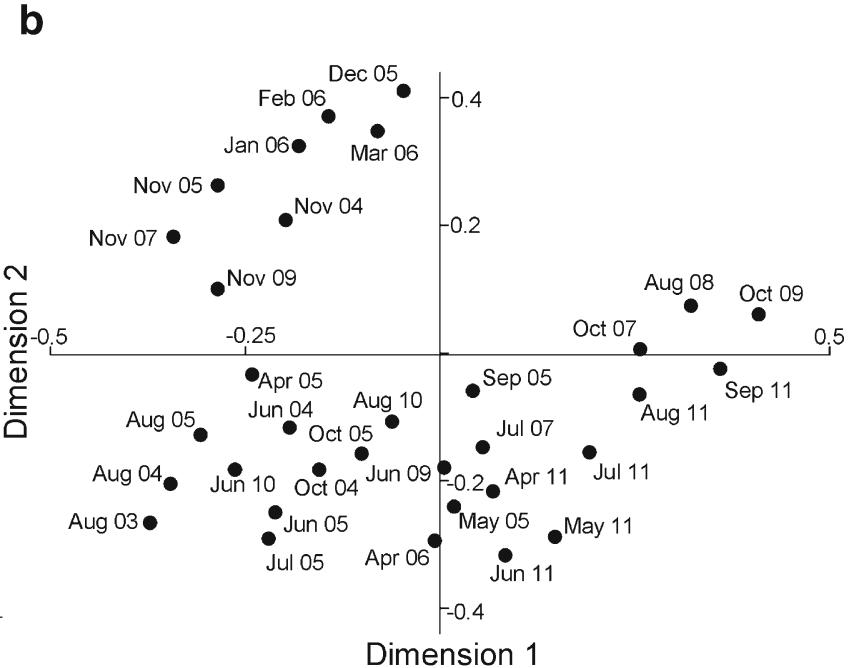

Curtis dissimilarity index calculated from fish density data. Months are given with correspondent year signs

characteristic of the NWBS during summer (Knowler et al. 2001; Kideys 2002). The absence of any significant correlation between seasonal Danube outflow and environmental variables (above all salinity) near Zmiinyi Island could be attributed to the fact that the island is located near the northern edge of the Danube Delta, while the sea currents run primarily from north to south along the coast in this region (Klimok et al. 1990; Agafonov et al. 2000; Oguz et al. 2002).

Fish community composition and general fish diversity

Species composition in the Zmiinyi waters was quite different compared to the fish communities typically found in the NWBS. Despite the small size of the researched area, the

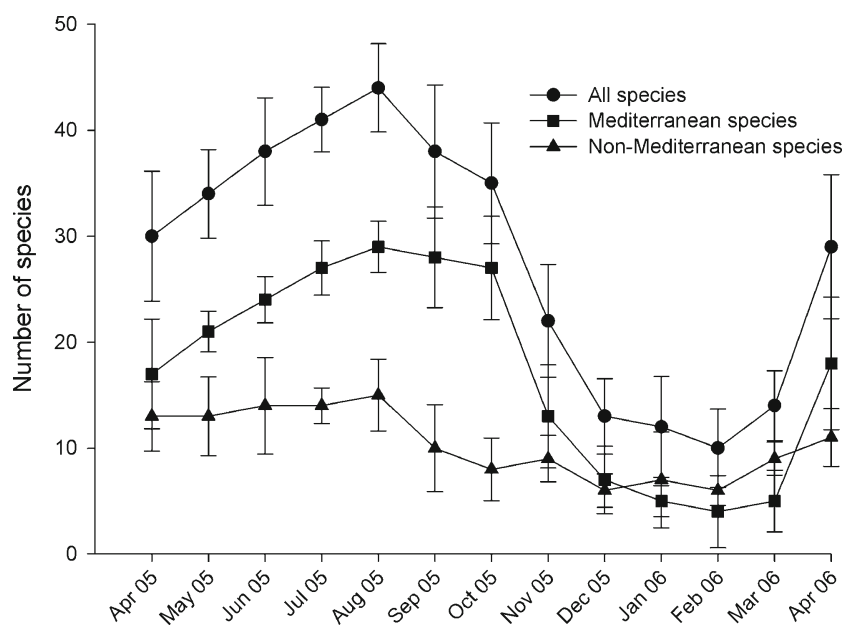

Fig. 6 Species richness over the period of continuous observation of the fish community 
Table 2 Summary of the stepwise multivariate regression models

\begin{tabular}{llllll}
\hline Dependent variable & $\mathrm{X}_{\mathrm{i}}$ & $\begin{array}{l}\text { Parameter } \\
\text { estimate }\end{array}$ & $P$ & VIF & Adjusted $R^{2}$ \\
\hline Overall species richness & Temperature & 0.548 & 0.022 & 6.364 & 0.928 \\
& Salinity & 0.343 & 0.035 & 5.986 & \\
& O $_{2}$ concentration & -0.205 & 0.048 & 8.852 & \\
& Danube outflow & 0.057 & 0.244 & 2.357 & \\
Mediterranean species richness & Temperature & 0.606 & 0.017 & 7.019 & \multirow{2}{*}{0.943} \\
& Salinity & 0.412 & 0.027 & 4.622 & \\
& O $_{2}$ concentration & -0.244 & 0.043 & 9.086 & \\
& Danube outflow & -0.121 & 0.305 & 2.563 & \\
Non-Mediterranean species richness & Temperature & 0.386 & 0.038 & 6.211 & 0.788 \\
& Salinity & 0.216 & 0.068 & 6.584 & \\
& O concentration & -0.098 & 0.172 & 7.017 & \\
& Danube outflow & 0.088 & 0.255 & 1.592 & \\
& & & &
\end{tabular}

species detected in our study constitute $71 \%$ of the species list for the Danube region of the Black Sea, and more than $60 \%$ of the species list for the NWBS as a whole (Zaitsev et al. 2006). Such a high species number together with high proportion of demersal species makes the fish community in the Zmiinyi Island area distinct from those characteristic for the NWBS (Zaitsev et al. 2006), but close to communities observed off the southern coast of the Crimean peninsula (Boltachev 2003). A plausible explanation for this is that Zmiinyi Island, being the only patch of rocky landscape in the NWBS, shares similar features with landscapes characteristic of the southern coast of Crimea.

The Bray-Curtis dissimilarity dendrogram, MDS and CCA show the crucial role of such factors as temperature and salinity in fish community composition, with oxygen concentration and Danube runoff having a lower effect. Moreover, temperature and salinity rendered a different influence on Mediterranean and non-Mediterranean fish species.

Analysis of the ichthyofauna structure by the Bray-Curtis dendrogram and MDS ordination shows an evident split of months between "Warm season" and "Cold season" groups. This grouping was further confirmed by CCA ordination and by the pattern of correlations between temperature and fish community parameters.

In the constrained ordination of CCA, axes 1 and 2 together were found to explain a high percentage of the variance of the species-environment bi-plot. The first axis represented a strong relationship between fish fauna and temperature fluctuations over the period of research; temperature and salinity were shown to be the most important physicochemical variables influencing the variation in community composition. The species group that experienced the strongest positive influence of these two factors was of the
Fig. 7 Fluctuations of the species community parameters over the continuous period of observation

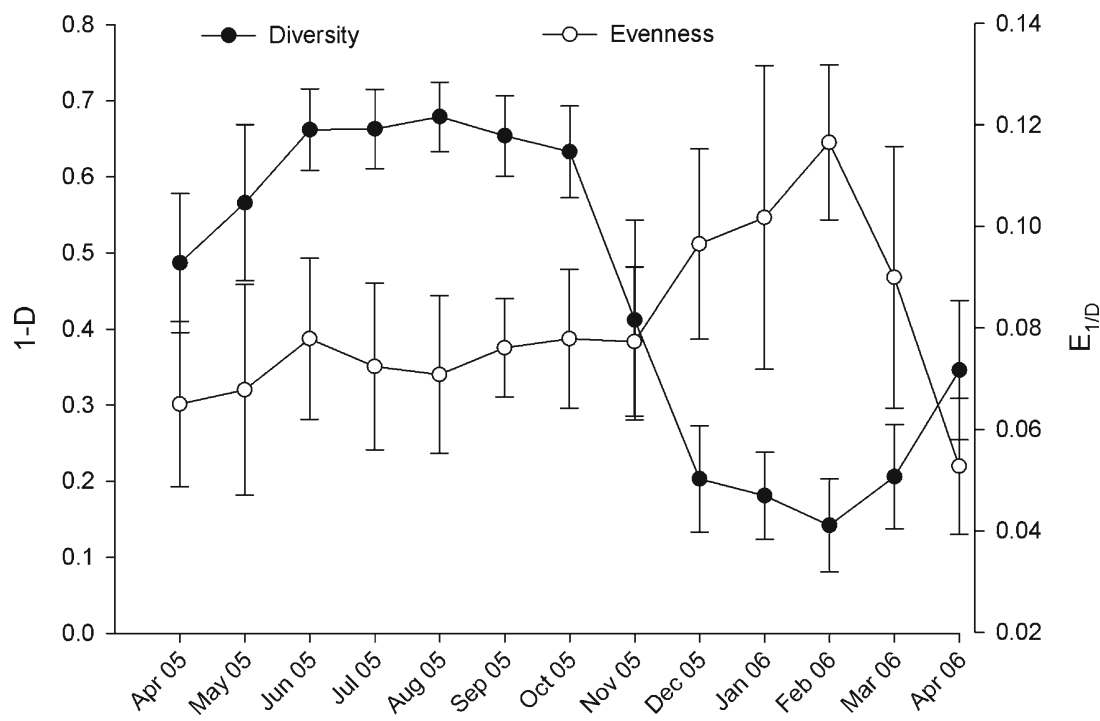


Fig. 8 Estimates of the temperature distribution of catchability (q). The mean $\mathrm{q}$ value has been set to 1 to facilitate comparison between species. Rows from top to bottom: non-Mediterranean pelagic species, Mediterranean pelagic species, nonMediterranean demersal species, Mediterranean demersal species. Species codes correspond to those given in Table 1

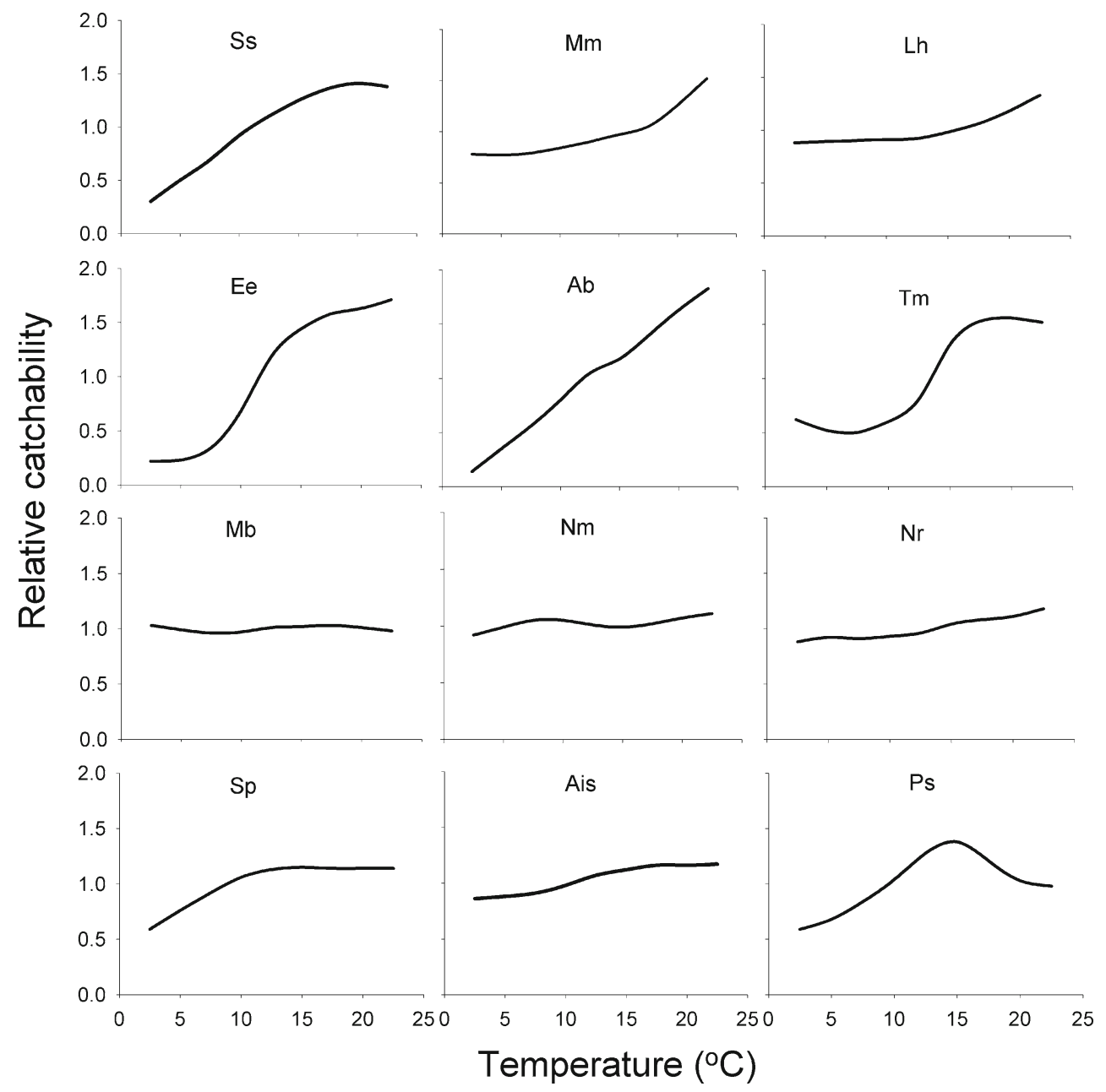

exclusively Mediterranean origin and was caught only during the "Warm season" months of the Bray-Curtis dendrogram. Conversely, in a group of species caught predominantly during the "Cold season", all but one were non-Mediterranean. The only Mediterranean species in this cluster, Pegusa lascaris, prefers sandy areas such as those present near Zmiinyi Island, instead of the muddy areas common of the Danube Delta neighborhood (Cabral 2000), and has one of its spawning peaks during the February-April period (Pajuelo and Lorenzo 2008). So, the increase in its abundance in a period of low temperature could be potentially associated with spawning activity.

Seasonal changes in fish community assemblage

In our research, we obtained higher coefficients of correlation between temperature and salinity for Mediterranean species richness than between these environmental factors and overall or non-Mediterranean species richness. This suggests the major contribution of the Mediterranean group of fishes to the fluctuations in the overall fish community structure. This also confirms the higher positive sensitivity of Mediterranean species to the changes in temperature and salinity compared with non-Mediterranean fishes, a conclusion which was already displayed by the CCA ordination.

The negative correlation between species richness and dissolved oxygen found in our research is apparently not biologically meaningful: most probably, this is a result of the partial negative correlation between temperature and oxygen concentration variables rather than an indication of a tolerance to the lack of oxygen developed by the fish community. Therefore, any negative effect of the decrease in dissolved oxygen concentration on species richness is masked by the synchronized stronger positive effect of water temperature, as has been shown previously for other temperate water areas (Koutrakis et al. 2000). Since Mediterranean species are more sensitive to water temperature, this provides additional indirect evidence of their primary role in determining the community parameters.

According to the data collected, the substantial seasonal changes of the water volume ejected from the Danube Delta do not have a significant impact on the fish community. Therefore, despite that the Danube runoff was shown to be a long-term (interdecadal and interannual) modulating factor 
for the ichthyofauna in the NWBS, we do not have enough data to support the hypothesis that Danube outflow is a seasonal modulating factor for the fish community in the studied waters.

One of the key indicators of the current status and future perspectives of a given ecosystem is its stability, which has been repeatedly shown to be critically dependent on species diversity (Ives and Carpenter 2007). Intuitively, one might expect species richness and species evenness to be positively correlated with species diversity (Cotgreave and Harvey 1994; Wilsey et al. 2005). Therefore, observing a positive correlation between species richness and diversity, but negative or no correlation between diversity and evenness, might tempt researchers to put lower credence in such a dataset when assessing the ecosystem conditions. However, several studies have demonstrated that species diversity and the evenness of relative abundance are not necessarily positively related (Buzas and Hayek 1996; Stirling and Wilsey 2001; Wilsey et al. 2005). Indeed, in dominanceorientated marine communities, non-significant or negative relationships between community parameters such as those observed in our dataset may represent the norm (Birch 1981).

In our study, we found that both Mediterranean and non-Mediterranean species richness positively correlates with the overall diversity index. However, the $r_{\mathrm{s}}$ value for Mediterranean species richness was much higher (0.969 vs. 0.64). This suggests Mediterranean species to be the key shaping group for the diversity index of the studied fish community.

Therefore, in our research, we have revealed that the two species groups (Mediterranean and non-Mediterranean) that form the fish community in Zmiinyi Island waters have different sensitivities to environmental factors (especially to temperature and salinity) and have different impacts on the overall community composition. The multiplicity and higher sensitivity to fluctuations in environmental factors allow Mediterranean species to determine the changes of the fish community parameters on a seasonal time scale.

Fluctuations in community parameters

and their underlying mechanisms

The wide spectrum of ecological, behavioral, physiological, and fishery characteristics inherent in the species described in our study makes it likely that several different mechanisms contribute to fluctuations in individual species abundance in Zmiinyi Island waters. For pelagic species, the hypothesis concerning the pivotal role of seasonal migrations for wintering (to the south of the Black Sea and further through the Bosporus strait) and for grazing and fattening (back to the north) has substantial observational support. Another potentially important factor is commercial fisheries in the Black Sea, which are now based almost exclusively on pelagic fishes (Caddy 1993; Prodanov et al. 1997; Knowler et al. 2001). Since the peak of commercial fishery in the Black Sea falls in the summer months, the decrease in catchability of pelagic species during the "Cold season" supports the hypothesis that seasonal migrations are the major factor shaping their abundance in the NWBS.

In contrast, demersal fishes in the NWBS are subject to very little industrial fishing. To the best of our knowledge, there are also no data about regular migrations of this species group from the NWBS to other Black Sea regions. Nevertheless, seasonal vertical migrations such as those shown for Psetta maxima off the southern Black Sea coast (Yoseda et al. 2002) could potentially affect the distribution pattern of demersal fishes in our study area and explain fluctuations in Mediterranean species catchability observed in this ecological group (Scorpaena porcus, Aidablennius sphynx, Parablennius sanguinolentus). However, such descriptive approaches of catchability assessment as we used in our study applied to a population of unknown size provide less accuracy and predictive power than "mechanistic" methods (Arreguín-Sánchez 1996; Wilberg et al. 2009), which combine continuous sampling with full population counts in the sampling areas performed by echolocation or rapid depletion trials, or with capture-recapture approaches (Carothers 1973; Dailey et al. 1986; Arreguín-Sánchez 1996; Speas et al. 2004). Therefore, further studies based on these "mechanistic" methods should be conducted for an accurate assessment of association between species catchability and hydrographic variables in Zmiinyi Island waters.

Since the physical environment being recognized as the main factor driving biological diversity and influencing essentially all processes in the sea ecosystem (Akin et al. 2005), empirical analyses of a type we performed allow the formulation of hypotheses concerning the relationships between the abiotic environment, productive processes, and population dynamics.

The Zmiinyi Island area is inhabited by species that represent a wide range of conservation status: from the "critically endangered" group of IUCN Red List (Huso huso, Acipenser stellatus) to the objects of commercial fishery (Sprattus sprattus, Alosa maeotica, Merlangius merlangus). Since a thorough understanding of the specific influences of environmental factors at different time scales is needed for reliable assessment of living marine resources (Rice 2001), the results of our study will facilitate the integration of environmental indices into conservation activity as well as ecosystem-based fisheries modeling and forecasting in the Black Sea.

Acknowledgments Authors thank Roman Sizo (NGO "Centre of Regional Studies", Odesa, Ukraine) and Evgeniy Gazetov (Odesa National Mechnikov University) for the map preparation. 


\section{References}

Agafonov E, Kaminsky S, Kukushkin A, Prokhorenko Y (2000) Spatial structure and variability of fields of currents, attenuation factor of light, and temperature in the surface layer of the northwest part of the Black Sea. Phys Oceanogr 10(4):351-364

Akin S, Buhan E, Winemiller KO, Yilmaz H (2005) Fish assemblage structure of Koycegiz Lagoon-Estuary, Turkey: Spatial and temporal distribution patterns in relation to environmental variation. Estuar Coast Shelf Sci 64(4):671-684

Almada F, Henriques M, Levy A, Pereira A, Robalo J, Almada VC (2008) Reclassification of Lepadogaster candollei based on molecular and meristic evidence with a redefinition of the genus Lepadogaster. Mol Phylogenet Evol 46(3):1151-1156

Arreguín-Sánchez F (1996) Catchability: a key parameter for fish stock assessment. Rev Fish Biol Fish 6(2):221-242

Artüz ML (1999) Inventory of existing species and their habitats in the Bosporus area. Oceonata 112(1):552-564

Aubrey D, Moncheva S, Demirov E, Diaconu V, Dimitrov A (1996) Environmental changes in the western Black Sea related to anthropogenic and natural conditions. J Mar Syst 7(2-4):411-425

Birch DW (1981) Dominance in Marine Ecosystems. Am Nat 118 (2):262-274

Boltachev A (2003) The current state of biodiversity of coastal waters of Crimea (Black Sea sector) [in Russian]. In: Ichthyofauna of the Black Sea coast of Crimea. Gidrofizika, Sevastopol, pp 364-379

Braak CJFT (1986) Canonical Correspondence Analysis: A New Eigenvector Technique for Multivariate Direct Gradient Analysis. Ecology 67(5):1167-1179

Braak CJFT (1994) Canonical community ordination. Part I: Basic theory and linear methods. Ecoscience 1(2):127-140

Braak CJFT, Verdonschot PFM (1995) Canonical CorrespondenceAnalysis and Related Multivariate Methods in Aquatic Ecology. Aquat Sci 57(3):255-289

Buzas MA, Hayek L-AC (1996) Biodiversity Resolution: An Integrated Approach. Biodivers Lett 3(2):40-43

Cabral H (2000) Distribution and abundance patterns of flatfishes in the Sado estuary, Portugal. Estuar Coast 23(3):351-358

Caddy J (1993) Contrast Between Recent Fishery Trends and Evidence for Nutrient Enrichment in Two Large Marine Ecosystems: the Mediterranean and Black Seas. In: Sherman K, Alexander LM, Gold BD (eds) Large Marine Ecosystems: Stress, Mitigation, and Sustainability. AAAS Press, Washington

Carothers AD (1973) The Effects of Unequal Catchability on Jolly-Seber Estimates. Biometrics 29(1):79-100

Chaschin AK (1996) The Black Sea populations of anchovy. Sci Mar 60(2):219-225

Cotgreave P, Harvey P (1994) Evenness of Abundance in Bird Communities. J Anim Ecol 63(2):365-374

Dailey J, Matlock GC, Hegen HE (1986) Catchability Coefficients for Coastal Fishes Caught in 366-Meter and 732-Meter Long Trammel Nets Struck with Noise and Rotenone. Estuaries 9 (4):348-355

Daskalov GM (2003) Long-term changes in fish abundance and environmental indices in the Black Sea. Mar Ecol Prog Ser 255:259-270

Edgington ES (1995) Randomization tests, 3, rev. and expandedth edn. Marcel Dekker, New York

Froese R, Pauly D (2011) FishBase. www.fishbase.org, 10/2011.

Galtsoff PS (1924) Seasonal Migrations of Mackerel in the Black Sea. Ecology 5(1):1-5

Griffiths SP (2001) Factors Influencing Fish Composition in an Australian Intermittently Open Estuary. Is Stability Salinity-Dependent? Estuar Coast Shelf Sci 52(6):739-751
Harrison TD, Whitfield AK (2006) Temperature and salinity as primary determinants influencing the biogeography of fishes in South African estuaries. Estuar Coast Shelf Sci 66(1-2):335-345

Horinouchi M (2009) Horizontal gradient in fish assemblage structures in and around a seagrass habitat: some implications for seagrass habitat conservation. Ichthyol Res 56(2):109-125

Ives AR, Carpenter SR (2007) Stability and diversity of ecosystems. Science 317(5834):58-62

Jaureguizar AJ, Menni R, Guerrero R, Lasta C (2004) Environmental factors structuring fish communities of the Río de la Plata estuary. Fish Res 66(2-3):195-211

Jennings GH (1996) European sea fishes: Gibraltar to Norway: the 1996 pocketbook: an identification guide to recorded species. Calypso, London

Kideys AE (2002) Ecology. Fall and rise of the Black Sea ecosystem. Science 297(5586):1482-1484

Klimok V, Makeshov K, Pertseva M, Rybalka V (1990) On numerical modelling of currents over the north-west shelf of the Black Sea. Phys Oceanogr 1(4):271-278

Knowler D, Barbier E, Strand I (2001) An Open-Access Model of Fisheries and Nutrient Enrichment in the Black Sea. Mar Resour Econ 16(3):195-217

Koutrakis ET, Kokkinakis AK, Eleftheriadis EA, Argyropoulou MD (2000) Seasonal changes in distribution and abundance of the fish fauna in the two estuarine systems of Strymonikos gulf(Macedonia, Greece). Belg J Zool 130:43-50

Kutner M (2004) Applied linear regression models, 4th edn. McGrawHill, London

Lande R, DeVries PJ, Walla TR (2000) When species accumulation curves intersect: implications for ranking diversity using small samples. Oikos 89(3):601-605

Maes J, van Damme PA, Taillieu A, Ollevier F (1998) Fish communities along an oxygen-poor salinity gradient (Zeeschelde Estuary, Belgium). J Fish Biol 52(3):534-546

Mee LD (1992) The Black Sea in crisis: A need for concerted international action. Ambio 21(4):278-286

Miller PJ, Loates M (1997) Fish of Britain \& Europe. HarperCollins, London

Nelson JS (1994) Fishes of the world, 3rd edn. Wiley, New York

Oguz T, Gilbert D (2007) Abrupt transitions of the top-down controlled Black Sea pelagic ecosystem during 1960-2000: Evidence for regime-shifts under strong fishery exploitation and nutrient enrichment modulated by climate-induced variations. Deep Sea Res Part I 54(2):220-242

Oguz T, Malanotte-Rizzoli P, Ducklow HW, Murray JW (2002) Interdisciplinary studies in integrating the Black Sea Biogeochemistry and Circulation Dynamics. Oceanography 15(3):4-11

Pajuelo JG, Lorenzo JM (2008) Reproductive characteristics of the sand sole Pegusa lascaris (Soleidae), from the eastern-central Atlantic. J Mar Biol Assoc UK 88(3):629-635

Prodanov K, Mikhailov K, Daskalov G, Maxim C, Chashchin A (1997) Environmental management of fish resources in the Black Sea and their rational exploitation. Studies and Reviews - General Fisheries Council for the Mediterranean (FAO), April 1997 edn. FAO, Rome.

Puzanov I (1965) Successive stages of the Black Sea mediterraneization: new data [in Russian]. Gidrobiol Zh 1(2):54-56

Rice J (2001) Implications of variability on many time scales for scientific advice on sustainable management of living marine resources. Prog Oceanogr 49(1-4):189-209

Serena F (2005) Field identification guide to the sharks and rays of the Mediterranean and Black Sea. Food and Agriculture Organization of the United Nations, Rome

Slastenenko EP (1959) Zoogeographical review of the Black Sea Fish Fauna. Hydrobiologia 14(2):177-188 
Smith B, Wilson JB (1996) A Consumer's Guide to Evenness Indices. Oikos 76(1):70-82

Soberon J, Llorente J (1993) The Use of Species Accumulation Functions for the Prediction of Species Richness. Conserv Biol 7 (3): $480-488$

Speas DW, Walters CJ, Ward DL, Rogers RS (2004) Effects of Intraspecific Density and Environmental Variables on Electrofishing Catchability of Brown and Rainbow Trout in the Colorado River. N Am J Fish Manag 24(2):586-596

Stirling G, Wilsey B (2001) Empirical Relationships between Species Richness, Evenness, and Proportional Diversity. Am Nat 158 (3):286-299

Svetovidov AN (1964) Fishes of the Black Sea [in Russian]. Nauka, Moscow

Swain DP, Poirier GA, Sinclair AF (2000) Effect of water temperature on catchability of Atlantic cod (Gadus morhua) to the bottomtrawl survey in the southern Gulf of St Lawrence. ICES J Mar Sci 57(1):56-68

Thiel R, Sepúlveda A, Kafemann R, Nellen W (1995) Environmental factors as forces structuring the fish community of the Elbe Estuary. J Fish Biol 46(1):47-69

Tokarev Y, Shulman G (2007) Biodiversity in the Black Sea: effects of climate and anthropogenic factors. Biodiversity in Enclosed Seas and Artificial Marine Habitats. In: Relini G, Ryland J, Dumont HJ (eds) Developments in Hydrobiology, vol 193. Springer, Netherlands, pp 23-33
Ward P, Myers RA (2005) Inferring the depth distribution of catchability for pelagic fishes and correcting for variations in the depth of longline fishing gear. Can J Fish Aquat Sci 62(5):1130-1142

Wilberg MJ, Thorson JT, Linton BC, Berkson J (2009) Incorporating Time-Varying Catchability into Population Dynamic Stock Assessment Models. Rev Fish Sci 18(1):7-24

Wilsey BJ, Chalcraft DR, Bowles CM, Willig MR (2005) Relationships among indices suggest that richness is an incomplete surrogate for grassland biodiversity. Ecology 86(5):1178-1184

Wolfinger R, O'Connell M (1993) Generalized linear mixed models: a pseudo-likelihood approach. J Stat Comput Sim 48(3-4):233-243

Woodhead PMJ (1994) Effects of Tide Gates on the Fish Community of the East River. Ann NY Acad Sci 742(1):57-68

Yoseda K, Sahin T, Üstündağ C, Ciftci Y, Amaoka K (2002) Seasonal Distribution and Migration Pattern of the Turbot Psetta maxima in the Eastern Black Sea, Republic of Turkey. Turk J Fish Aquat Sci $2: 5$

Zaitsev Y, Alexandrov B, Minicheva G (2006) North-Western Part of the Black Sea: Biology and Ecology [in Russian]. Naukova Dumka, Kyiv

Zaitsev YP (1992) Recent changes in the trophic structure of the Black Sea. Fish Oceanogr 1(2):180-189

Zengin M, Dinçer C (2006) Distribution and Seasonal Movement of Atlantic Bonito (Sarda sarda) Populations in the Southern Black Sea Coasts. Turk J Fish Aquat Sci 6:57-62 